\title{
Siniestralidad vial en la frontera norte de Tamaulipas. Enfoque en los procesos administrativos de control
}

\section{Road accidents rate in the northern border of Tamaulipas. The approach on the administrative control processes}

Recibido el 26 de febrero de 2016. Aceptado el 12 de diciembre de 2016.

*Autor para correspondencia: Yolanda Velázquez Narváez, correo electrónico: yovelazquez@docentes.uat.edu. $\mathrm{mx}$

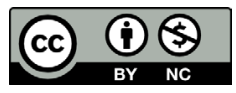

Todos los contenidos de Estudios Fronterizos se publican bajo la licencia Creative Commons Atribución no comercial 2.5 México, y pueden ser usados gratuitamente para fines no comerciales, dando el crédito a los autores y a la revista Estudios Fronterizos.

\author{
Yolanda Velázquez Narváez a* (iD (http://orcid.org/0000-0001-5591-8474) \\ Benito Zamorano González a (i) (http://orcid.org/0000-0003-0422-3001) \\ Lucía Ruíz Ramos a (iD (http://orcid.org/0000-0002-7122-6758)
}

\begin{abstract}
a Universidad Autónoma de Tamaulipas, Unidad Académica Multidisciplinaria de Matamoros, México, correos electrónicos: yovelazquez@docentes.uat.edu.mx, bzamorano@docentes.uat.edu. mx, luruiz@docentes.uat.edu.mx
\end{abstract}

\section{Resumen}

El objetivo del presente estudio es identificar fallas en los procesos administrativos de control que favorecen las conductas de riesgo de los operadores de vehículos. Mediante el análisis del contexto de la frontera norte de Tamaulipas y las estadísticas más recientes en siniestralidad vial, complementado con un estudio exploratorio en una muestra de 535 individuos identificando problemáticas asociadas a la deficiencia de dichos procesos y teniendo como limitación que las variables son las propias del contexto geográfico, se encontró que la principal causa de los accidentes viales en el municipio son las conductas de riesgo de los conductores de vehículos; así mismo, que existen fallas en los procesos administrativos de control, las cuales, favorecen estas conductas. Se aporta información para realizar intervenciones sobre la problemática de la accidentalidad vial que es considerado un problema de salud pública y, como conclusión, se evidencia que existen deficiencias en los procesos administrativos de control sobre vialidad que favorecen las conductas de riesgo de los conductores.

Palabras clave: accidentes, vialidad, riesgo, sistema, frontera de Tamaulipas.

\section{Abstract}

The objective of this study is to identify the failures in the administrative control processes that favor risky behaviors in the operators of motor vehicles. Through the analysis of the context of the northern border of Tamaulipas and the most recent accident rate statistics, complementing it with an exploratory study

CÓMO CITAR: Velázquez, Y., Zamorano, B. \& Ruíz, L. (2017). Siniestralidad vial en la frontera norte de Tamaulipas. Enfoque en los procesos administrativos de control [Road accidents rate in the northern border of Tamaulipas. The approach on the administrative control processes]. Estudios Fronterizos, 18(36), 1-24, doi: 10.21670/ref.2017.36.a01 
done with a sample of 535 subjects, identifying issues associated with the deficiencies of said processes, and having as limitation the fact that the variables are inherent to the geographic context, it was found that the main causes of road accidents in the municipality are the risky behaviors of the vehicle operators; moreover, there are failures in the administrative control processes, which favor these behaviors. Information is provided to carry out interventions regarding public health and, to conclude, evidence is provided on the existence of differences in the administrative control processes on road safety that favor the risky behaviors of the drivers.

Keywords: accidents, roads, risk, system, Tamaulipas border.

\section{Introducción}

Los accidentes de tránsito se han convertido en un problema de salud pública a nivel mundial (Alfaro-Basso, 2008). De acuerdo con la Organización Mundial de la Salud (oms) (2015b), estos eventos causan anualmente la muerte de aproximadamente 1.25 millones de personas alrededor del mundo, siendo el grupo de 15 a 29 años de edad el mayormente afectado, y esta cifra se ha mantenido estable a lo largo de casi 10 años. Al respecto, la Dirección General de Tránsito Municipal (s.f.) de Ciudad Juárez, Chihuahua, México, afirma que en la región de las Américas alrededor de cinco millones de personas son lesionadas como consecuencia de accidentes viales. Además de considerarse en la actualidad como la primera causa de muerte en personas de 5 a 14 años de edad y la segunda causa de muerte en personas de 15 a 44 años de edad en dicha región. Así mismo, "los países de Latinoamérica y el Caribe superan por casi el doble la tasa de muertes en siniestralidad infantil por accidentes de tránsito de los países desarrollados" (Gallego et al., 2015, p. 1).

Parece existir una relación directa entre las características económicas de las naciones y la tasa de mortalidad por eventos de tráfico. De acuerdo con cifras del informe de la situación mundial de la seguridad vial de la oms (2015a), de un total de 163 países, 68 registraron un incremento en la cantidad de defunciones por accidentes viales desde el año 2010, de los cuales $84 \%$ corresponde a países de ingresos bajos o medios. De los 79 países que registraron una disminución en el número de muertes por esta causa, $56 \%$ corresponde a naciones de ingresos bajos y medios. No obstante, las tasas de mortalidad de los países de ingresos bajos, representan más del doble de aquéllos registrados en los países con ingresos altos. Por otro lado, a pesar de que $90 \%$ de las defunciones ocasionadas en accidentes de tránsito está distribuido entre los países con ingresos bajos y medios, estos concentran únicamente $54 \%$ de los vehículos existentes en el mundo.

En el contexto nacional, según cifras del Programa Sectorial de Salud (2014), durante el 2012 se registró en México un incremento de 2.93\% de defunciones relacionadas a accidentes viales en relación al año anterior. En este sentido, la Secretaría de Salud (ss) (2012), manifiesta que, en el país, los accidentes automovilísticos son la causa de muerte de alrededor de 24000 personas anualmente, ocupando el séptimo lugar mundial en accidentes viales. En este contexto, México ocupaba desde el año 2009, la décima posición en número de muertes ocasionadas por accidentes de tránsito de un total de 32 países (Cable News Network México [CNN México], 2014). 
La tasa de mortalidad por esta causa significó, para el año 2012, 14.6 defunciones por cada 100000 habitantes, mientras que para el año 2014 se registraron 378240 accidentes de tránsito en las zonas urbanas de México, de los cuales 1.1\% resultaron en fatalidades con un total de 4708 víctimas; de ellas, $43 \%$ correspondieron a los conductores de los vehículos involucrados (Instituto Nacional de Estadística y Geografía [Inegi], 2015). En este sentido, la tendencia sobre el incremento en las estadísticas sobre accidentes viales y sus consecuencias, se ha proyectado desde hace más de una década. Cabrera, Velásquez y Valladares (2009), afirman que para el 2002 las naciones que reportaron a la oms defunciones violentas, determinaron como causa común de las mismas a los accidentes de tránsito. Las defunciones relacionadas a estos eventos representaron $23 \%$ del total de muertes. Respecto a los grupos de edad, los decesos derivados de accidentes viales fueron la segunda causa de dichas fatalidades en infantes y preadolescentes (5-14 años de edad), y en adolescentes y adultos jóvenes (15-29 años de edad), así como la tercera causa de decesos de adultos de 30 a 44 años de edad. Para el 2013 los accidentes de tránsito ya afectaban a 2.2\% de la población global (CNN México, 2014).

Así mismo, en un estudio realizado en 2003 por Arreola, Guzmán, Esquivel y Mock (2008), en el estado de Nuevo León, se encontró que dos terceras partes de las defunciones asociadas a este fenómeno, registradas durante el periodo de febrero a julio, fueron ocupantes de vehículos.

Es importante señalar que las pérdidas generadas por los accidentes de tránsito no se limitan a la integridad humana, —aunque esta pudiera resultar la afección más importante-. Alemany, Ayuso y Guillén (2013), resaltan las repercusiones económicas que estos conllevan. Al respecto, Aguilar-Zinser (2010) afirma que según la Organización para la Cooperación y el Desarrollo Económico (OCDE), los costos por accidentes de tránsito en los países miembros se calculan entre 2 y $5 \%$ del producto interno bruto (PIB), mientras que en México, de acuerdo con datos arrojados por el Sector Salud, el porcentaje del PIB es de 1.3. Según cifras de la Subsecretaría de Prevención y Promoción de la Salud de la Secretaría de Salud (ss, 2012), este porcentaje representa casi 130000 millones de pesos al año dedicados a la atención médica inmediata de los servicios de emergencias brindados a los lesionados, tratamientos médicos posteriores y daños materiales y físicos.

De esta manera, los accidentes viales representan altos costos para las dependencias de salud. La oms (citada en Ávila et al., 2008), asegura que por cada persona que fallece como consecuencia de estos eventos, en promedio se hospitaliza a 30 personas, mientras que otras 300 deben recibir atención en las unidades de urgencias. Aunado a lo anterior, alrededor de $43 \%$ de estos tardan un tiempo promedio de un año en recuperarse.

Por otro lado, cuando las víctimas son infantes, "las secuelas no se limitan a la pérdida o disfunción de un órgano, sino también a la interrupción del desarrollo, con secuelas que pueden durar toda la vida" (Bustos, Cabrales, Cerón y Naranjo, 2014, p. 69), lo que también conlleva costos respecto a terapias de rehabilitación, cirugías, medicamentos, entre otros, que muchas veces deben ser absorbidos por las dependencias de salud gubernamentales. De acuerdo con Kalantar, Dadgar y Ebrahimi (2014), cada año se registran de 20 a 50 millones de personas con discapacidad, debido a lesiones ocasionadas en accidentes de tráfico. Además estos eventos son la primera causa de fracturas maxilofaciales.

La situación es realmente alarmante y el panorama nada alentador. La Organización Panamericana de la Salud (ops) (2013), manifiesta que existe una alta probabilidad de que los traumatismos relacionados con accidentes viales se incrementen para el 
año 2030, llegando a ser la tercera causa de mortalidad. Sin embargo, a pesar de que existe información al respecto, la oMs (World Health Organization [wHo], 2013), asegura que los accidentes viales que generan lesiones no fatales, son pobremente documentados.

Por loanterior, esimportante que las investigaciones sean encaminadas a laidentificación de los factores de riesgo presentes en los accidentes de tráfico. No obstante, cabe señalar que, según Vázquez (2004), son diversos los factores que se encuentran asociados con un accidente vial, de ahí la complejidad de su estudio, pues dichos accidentes se derivan de múltiples causas que no siempre son identificadas correctamente.

Si bien estos eventos se presentan por múltiples causas, generalmente combinadas entre sí, si se considera que un elevado porcentaje de los accidentes de tránsito en el mundo son atribuidos al factor humano (Alfaro-Basso, 2008; Arias 2011), cuya actitud frente a la seguridad vial, está determinada por su adiestramiento, experiencias y valores (Adriasola, Olivares y Díaz, 1972, p. 12), se hace prioritario abordarlos desde esta perspectiva, de tal manera que los esfuerzos sean encaminados a la persuasión sobre la eliminación de las conductas de riesgo (oms, citado en Morales-Soto, AlfaroBasso y Gálvez-Rivero, 2010).

Sin embargo, si bien es cierto que las conductas de riesgo están constantemente presentes en la ocurrencia de eventos de tránsito, estas solo pueden considerarse como las causas inmediatas anteriores al accidente, mas no como su causa raíz. De acuerdo con Cortés (2001), cuando existen deficiencias en el ejercicio administrativo pueden generarse una serie de consecuencias, - acciones y condiciones-, que desencadenan un accidente.

Por lo anterior, se realiza el presente trabajo de investigación con el objetivo de detectar fallas en los procesos administrativos de control que pudieran impactar negativamente sobre las actitudes de los conductores de automóvil en la ciudad de Heroica Matamoros, Tamaulipas, México. De esta manera se pretende contribuir con información de interés para las autoridades competentes para el logro del primer objetivo del Programa Sectorial de Salud (2014, p. 43), en el rubro correspondiente a la seguridad vial: de "generar datos y evidencia científica para la prevención de lesiones ocasionadas por accidentes viales".

Para ello, se consideran las siguientes hipótesis:

1. La principal causa asociada a la ocurrencia de accidentes viales en el municipio de Matamoros Tamaulipas, corresponde a conductas de riesgo de los conductores de vehículos, que ponen en riesgo su integridad y la de terceros.

2. En la ciudad de Matamoros Tamaulipas, existen fallas en los procesos administrativos de control, lo cual representa un factor de riesgo asociado con los accidentes viales, ya que favorecen las conductas de riesgo.

\section{Factores de riesgo asociados a la siniestralidad vial}

Debe existir claridad en que, en la medida que se realice una oportuna y correcta identificación de los factores de riesgo asociados a los accidentes de tráfico, podrá hablarse entonces de una toma de acciones efectivas en materia de prevención, al 
eliminar o controlar las situaciones de riesgo, y como consecuencia, se podrá reducir el impacto negativo que estos eventos conllevan tanto en aspectos de salud, como sociales y económicos.

Cuando se habla de un factor de riesgo se está haciendo referencia a una condición, circunstancia, acción u omisión que aumenta la probabilidad de ocurrencia de un evento no deseado, en este caso, accidente. De acuerdo con Heinrich (citado en Meliá, Ricarte y Arnedo, 1998), una lesión resulta de una secuencia de factores donde el último de ellos es el accidente mismo.

Algunos factores de riesgo que se han asociado a los accidentes de tránsito son principalmente en relación al conductor, tales como:

1. La velocidad excesiva (Pérez-Núñez, Hijar, Celis e Hidalgo-Solórzano, 2014).

2. La ingesta de alcohol y drogas (Calafat, Adrover, Juan y Blay 2008; Dirección General de Tránsito Municipal, s.f.; Guanche, Martínez y Gutiérrez, 2007; Pérez-Núñez et al., 2014).

3. Conductas de riesgo (Morales-Soto et al., 2010; Sánchez, 2008).

4. Cansancio-fatiga (Rey, González y Egoavil, 2009; Rosales et al., 2009), y

5. Utilización de teléfono celular al conducir (Pérez-Núñez et al., 2014;

White, Hyde, Walsh y Watson, 2010).

Otras como condiciones de la vía, —se considera que los riesgos vinculados a ella en países subdesarrollados o en vías de desarrollo es mayor- (Medina, Borja y Flores, 2014); del vehículo y factores asociados al clima (Roth, 2016), han estado presentes en las investigaciones sobre el tema en menor grado.

Para Perrow (citado en Godoy, Escaudar, Jaca y Pinto, 2001), las situaciones de riesgo vistas a nivel del individuo o de un grupo de individuos, son realmente un problema de estructura organizacional. Este autor atribuye la ocurrencia de accidentes como consecuencia de la complejidad del sistema mismo.

Este enfoque es similar a la teoría de multicausalidad diseñada por Bird y Germain (1990), la cual parte de la premisa de que el origen de los accidentes (pérdidas), laborales es la falta de control en los procesos administrativos (Figura 1).

Figura 1: Modelo de causalidad de pérdidas

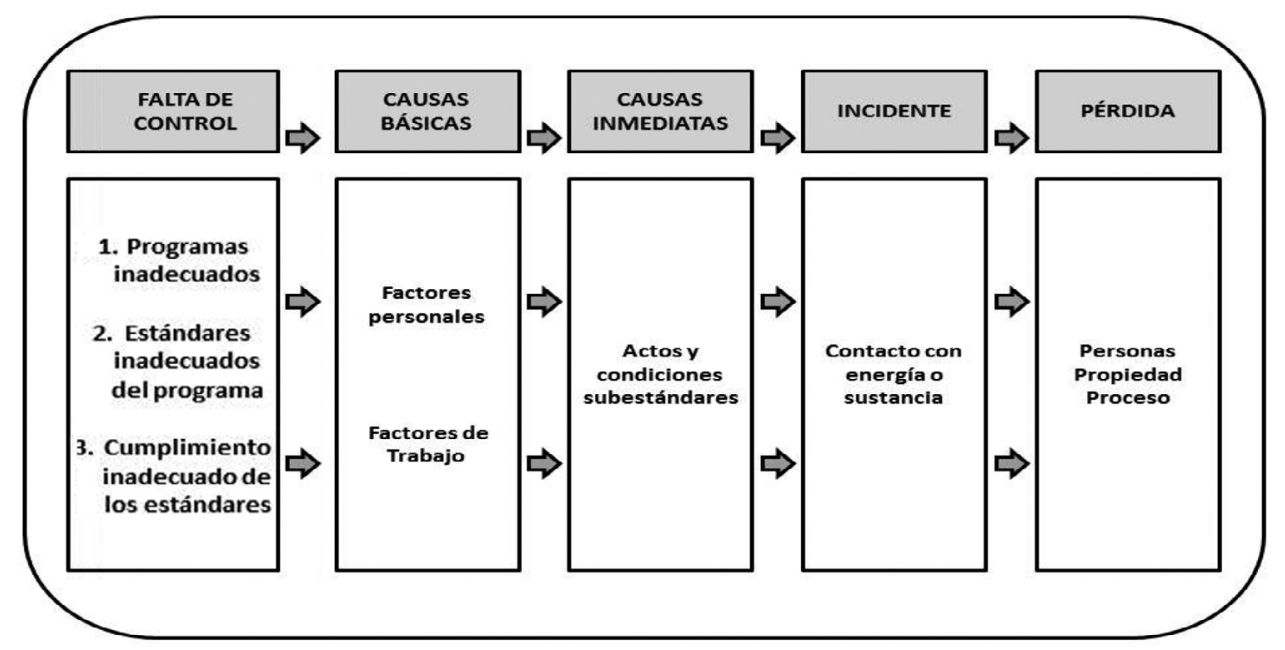

Fuente: Bird y Germain, 1990. 
Aunque esta teoría es antigua, continúa manteniéndose vigente, pues las estrategias encaminadas a los controles administrativos para prevención de riesgos es una actividad que se sigue llevando a cabo en la actualidad en los espacios laborales.

En este modelo se identifica la falta de control en los procedimientos y programas administrativos como la causa raíz que desencadena una serie de eventos que terminan en una pérdida (accidente), ya sea económica, de salud o ambas. Para el caso del presente estudio se sustituiría a los factores de trabajo, por factores ambientales (vía, señalización, clima), que son los que originarían las condiciones subestándares a las que se enfrenta el conductor en su trayecto. Esto incluye el diseño y construcción de vialidades adecuadas (incluyendo el alumbrado), que preferentemente deben ser consideradas desde la fase de planeación. Sin embargo, es común que en esta fase se pasen por alto condiciones importantes para la seguridad tanto del conductor, como del resto de los usuarios de las vías, ante lo cual, procedería la modificación de algunas condiciones que disminuyan riesgos de accidentes. No obstante, como lo señalan Quitsberg, Miranda y Ebel (2010), en muchas ocasiones estas modificaciones implican la realización de cambios importantes tanto en las vías como en el entorno físico, lo cual deriva en una inversión considerable que hace que su implementación no sea atractiva para las autoridades correspondientes.

De acuerdo con la teoría de Bird y Germain (1990), los procesos administrativos corresponden a la autoridad, quien será responsable de que los programas sean adecuados, contengan los estándares pertinentes y se asegure el cumplimiento de los mismos, aplicando las sanciones económicas o administrativas pertinentes de manera oportuna, evitando así la impunidad de actos no deseados y por lo tanto, disminuyendo su ocurrencia.

En otras palabras, los procesos administrativos de control, sean eficaces o deficientes, establecen la pauta del entorno social, el cual influye de manera indirecta en la conducta del individuo. Donas (2001), explica que el individuo se ve influenciado por la multiplicidad de factores de riesgo y factores de protección con los que interactúa en diferentes momentos de su existencia, haciéndolo más o menos vulnerable a sufrir un daño como consecuencia de una conducta adquirida, por ejemplo el no usar los dispositivos de seguridad al conducir.

Aunque los procesos públicos administrativos no son considerados como un factor de riesgo asociado a los accidentes viales en la mayoría de las investigaciones, existen trabajos como el del Comité Nacional de Prevención de Accidentes en Carreteras y Vialidades - CONAPrea (citado por Mendoza, Quintero y Mayoral, 2003), que identifica al sistema como uno de los cuatro factores primordiales que deben intervenir en la prevención de los accidentes viales, dentro del cual se insertan aspectos de planeación estratégica.

En este sentido, Ferrer, Smith, Espinosa, Cuellar y Raffo (2013), aseguran que de acuerdo con un análisis de la capacidad de gestión de la seguridad vial en Colombia, se identificó como punto débil en el sistema y que debe ser atendido en cuanto a la escasez de acciones coordinadas entre las diversas autoridades para promover un comportamiento favorable de los conductores de vehículos en términos del cumplimiento normativo se identificó como punto débil en el sistema y que debe ser atendido. Por otro lado, el sistema de expedición de licencias de conducir y homologación de vehículos resultó ser deficiente. Al respecto, Planzer (2005), encuentra que en el contexto de América Latina y el Caribe, la falta de atribuciones es un problema que reportan la mayoría de los países y considera que la opinión de la entidad dedicada a la seguridad de tránsito debiera tener peso sobre las decisiones 
respecto al sistema de multas, expedición de licencias de conducir, normas viales, entre otras, de tal manera que las decisiones administrativas estuvieran más fundamentadas y no se tomen de manera unilateral. Aunado a lo anterior, las medidas de control que se implementen, deben partir de un diagnóstico realista de la situación del país en materia de seguridad vial para posteriormente determinar las acciones a seguir para el logro de las metas y objetivos propuestos. Para lo cual, será necesario tomar acciones como las mencionadas por Arreola, Herrera, Cruz y Mock (2003), respecto a contar con un sistema informativo sobre el registro y monitoreo de las defunciones relacionadas con esta problemática, por lo que se hace necesaria la cooperación de las diferentes dependencias, tales como agentes viales, hospitales públicos y privados, el ministerio público, entre otros. Estos registros no solamente deben limitarse a las lesiones o pérdidas, sino a recolectar información sobre sus causas.

Partiendo de la idea de que, si bien el modelo de causalidad de pérdidas se generó desde un enfoque laboral, no es exclusivo de él y que en el caso de los accidentes viales las fallas en el proceso de control serían originadas desde el nivel de gestión, los procesos administrativos de control en cuanto a la seguridad vial, son un factor que debería ser considerado dentro de la multicausalidad de los accidentes de tráfico. Esto no significa que el sistema en sí mismo sea el responsable de la ocurrencia de estos eventos, sin embargo, en la medida que las actividades que de él se derivan sean eficientemente controladas, el impacto sobre la posibilidad del error humano será considerable.

\section{Contexto geográfico}

Tamaulipas es un estado de la República Mexicana ubicado al margen del Río Bravo, al noreste del país. Colinda al norte con Estados Unidos de América y se divide en 43 municipios. Ocupa el lugar número 13 de la República Mexicana, en relación con la cantidad de habitantes que tiene y cuenta con una población de 3268554 personas, de las cuales, $50.5 \%$ son mujeres y $49.5 \%$ son hombres, según cifras del Inegi (2010).

Durante el periodo 2012-2013, la tasa de mortalidad por accidentes viales en la entidad, se mantuvo por encima de la media nacional siendo de 16.2 y 15.3 respectivamente, como se muestra en la Figura 2. 
Figura 2: Gráfica de la tasa de mortalidad por lesiones ocasionadas por accidentes viales en las entidades federativas, México, 2012-2013

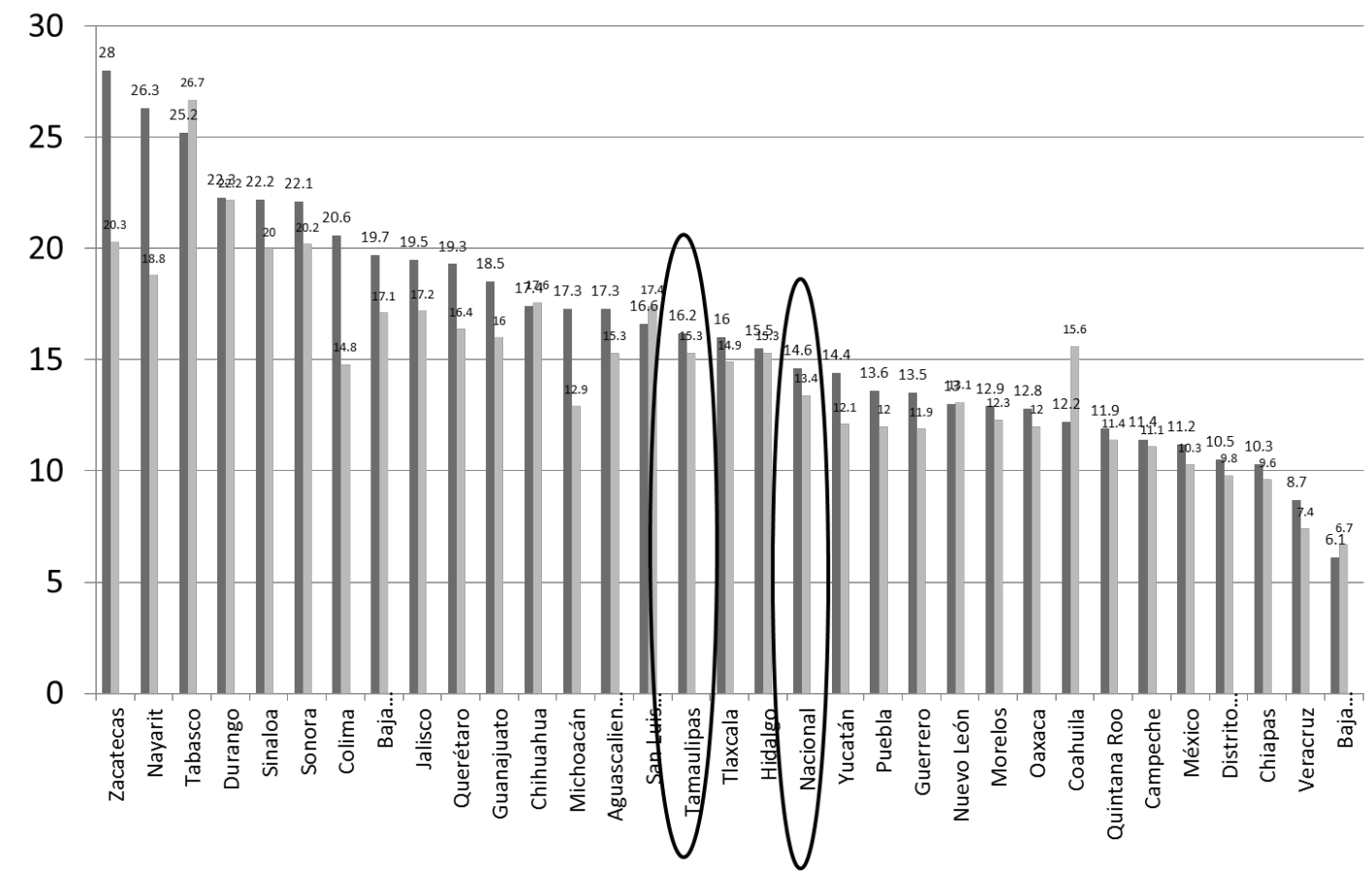

Fuente: Consejo Nacional para la Prevención de Accidentes (CONAPRA), 2014.

Además durante el 2014 la tasa de mortalidad fue de 15.4, lo que representó un aumento de $1.3 \%$ manteniéndose por arriba de la media nacional (ss, 2015). La tasa de mortalidad es uno de los indicadores en seguridad vial que deben ser monitoreados, por todos los niveles de gobierno, sin embargo no es el único, pues no todos los accidentes de tráfico concluyen en defunción.

Dentro de la entidad, los tres municipios que presentaron la mayor frecuencia de accidentes viales terrestres durante el año 2014, corresponden a la franja fronteriza, como se observa en la Tabla 1.

Tabla 1: Municipios con mayor incidencia de accidentes viales en Tamaulipas, 2014

\begin{tabular}{ll}
\hline Municipio & Habitantes \\
\hline Reynosa & 608891 \\
Heroica Matamoros & 489193 \\
Nuevo Laredo & 384033 \\
Ciudad Victoria & 321953 \\
Tampico & 297554 \\
Altamira & 212001 \\
Madero & 197216 \\
\hline
\end{tabular}

Fuente: Inegi, 2015. 
La ubicación geográfica de estos municipios, se presenta en la Figura 3.

Figura 3: Ubicación geográfica de los municipios con mayor registro de accidentes viales en Tamaulipas, 2014

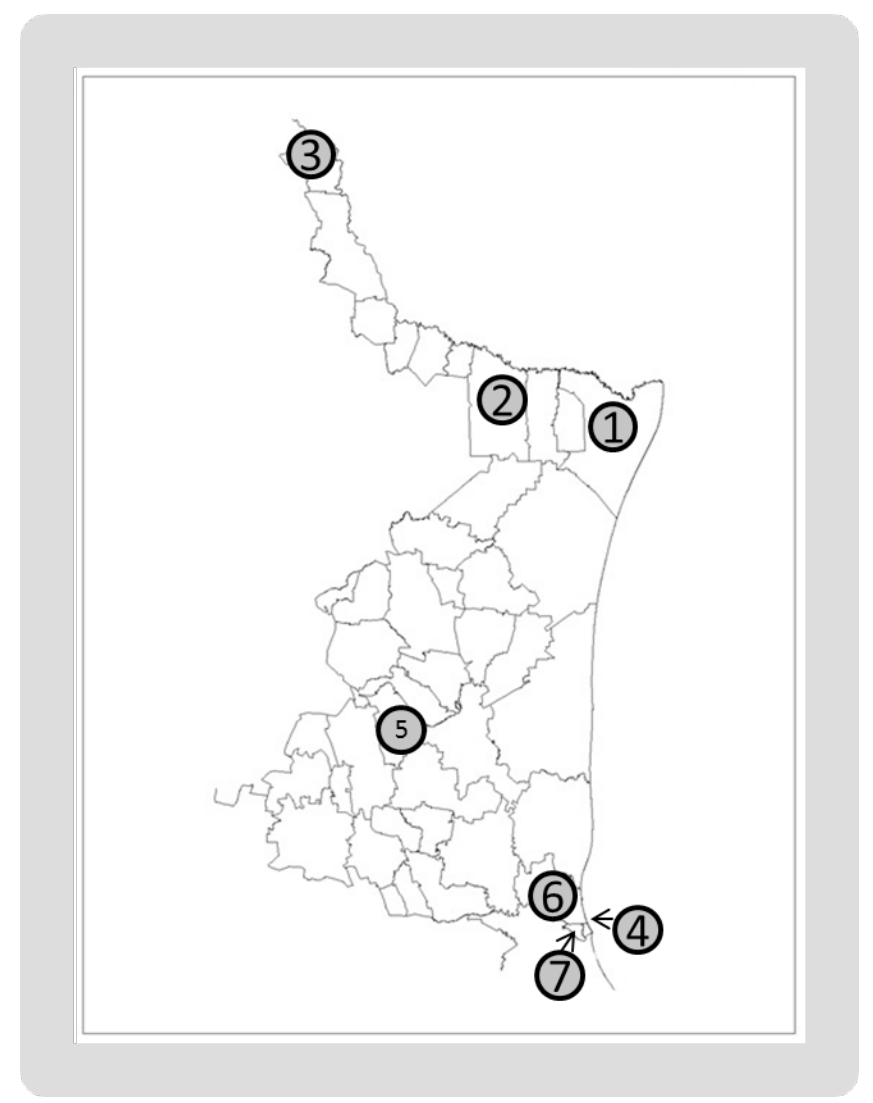

Fuente: Elaboración propia.

Aunque pudiera pensarse que la cantidad de accidentes se da en relación con la cantidad de población de cada municipio, esto no es del todo correcto, ya que según el último censo de población y vivienda del Inegi (2010) (Véase Tabla 2), el número de habitantes en estos municipios es el siguiente: 
Tabla 2: Distribución de la población por municipio, 2010

\begin{tabular}{lll}
\hline Lugar & Municipio & $\begin{array}{l}\text { Accidentes viales durante } \\
\text { el año 2014 }\end{array}$ \\
\hline 1 & Heroica Matamoros & 2190 \\
2 & Reynosa & 2139 \\
3 & Nuevo Laredo & 1682 \\
4 & Madero & 1216 \\
5 & Ciudad Victoria & 1080 \\
6 & Altamira & 804 \\
7 & Tampico & 721 \\
\hline
\end{tabular}

Fuente: Elaboración propia con base en datos del Inegi (2010).

En este sentido, siendo la población de Matamoros, menor que la de Reynosa por más de 100000 habitantes, en el año 2014 la superó con 51 accidentes vehiculares, de tal manera que la tasa de accidentes viales por cada 100000 habitantes para Reynosa fue de 351.29, mientras que para Matamoros fue de 447.67.

Respecto a los tres municipios con mayor ocurrencia de accidentes viales dentro de la entidad, se encuentran ubicadas al límite superior del estado, siendo frontera al norte con el valle del sur de Texas. Debido a lo cual, otra característica común entre ellas es la permanente presencia de tráfico vehicular extranjero e irregular del cual no existe registro oficial. Según cifras del Instituto Nacional de Ecología y Cambio Climático (citado en Zamorano, Peña, Parra, Velázquez y Vargas, 2015), la cantidad de vehículos registrados en Matamoros, ante la Secretaría de Finanzas es de 76533 mientras que en el "Reporte final de emisiones y parque vehicular de Matamoros y Reynosa Tamaulipas" la cantidad de vehículos activos asciende a 267290.

$\mathrm{Al}$ respecto, la Asociación Mexicana de la Industria Automotriz (citada en Martínez, 2012), estima que para el 2001 circulaban en el país entre 1.5 y 2.5 millones de vehículos irregulares, —también llamados autos chocolates - La diferencia significativa de las cifras se debe a la imposibilidad de tener un censo confiable de estos vehículos. En datos extraoficiales de diversas fuentes se ha calculado que más de 100000 vehículos extranjeros circulan por algunas ciudades de esta zona fronteriza. Esta tendencia se deriva de la facilidad de adquisición de un auto extranjero en comparación a la de un auto mexicano. El principal problema con ello es que a pesar de que existe la alternativa de regularizarlos y en algunos casos, nacionalizarlos y de esa manera legalizarlos, los costos de estos procesos son elevados, y al no haber una verdadera consecuencia por circular con vehículos no registrados, el propietario realiza un análisis costo-beneficio, concluyendo que le resulta más barato una sanción administrativa e incluso perder el vehículo, que pagar la legalización y el pago de tenencia. En este sentido, es importante señalar que esta situación representa un factor de riesgo potencial en la recurrencia de accidentes viales, ya que cuando el conductor infringe una ley de tránsito u ocasiona un accidente y se da a la fuga no hay forma de rastrearlo, puesto que aun cuando se tenga conocimiento del número de placas, estas no se encuentran registradas en México para vincularlas con el dueño del vehículo, e incluso muchas veces son placas sobrepuestas. De esta manera se incrementa la posibilidad de que el delito cometido quede en la impunidad y se repita. 
En Matamoros, se puede observar esta situación incluso en el transporte público, específicamente en taxis que circulan libremente por la ciudad, —en cifras extraoficiales se mencionan más de 300 vehículos, distribuidos en diferentes bases-. Desafortunadamente es común observar cómo los choferes de estos vehículos ilegales continuamente cometen actos riesgosos poniéndose en peligro a sí mismos y a otros usuarios de la vía.

Otro factor común, es la inestabilidad que existe respecto a los elementos de vigilancia vial, ya que por el contexto social que se vive en el estado desde hace algunos años, los policías viales (tránsitos), se muestran en las calles de forma intermitente, dejando pasar, en ocasiones, meses sin que haya presencia de estos elementos en las calles. En otros casos, estas atribuciones son asignadas a otros cuerpos como la milicia, o la policía estatal, cuyas funciones prioritarias difieren de la vigilancia del cumplimiento de reglas viales.

\section{Materiales y métodos}

Indudablemente existe gran variedad de trabajos de investigación sobre los factores de riesgo asociados a los accidentes viales, no obstante, la información respecto a la efectividad de los procesos administrativos de control es en extremo escasa. Si bien este tema es abordado en algunos de ellos, los datos generados son pertinentes para otros contextos. En la particularidad del estado de Tamaulipas, existen factores sociales y políticos que diferencian a la entidad del resto de las entidades federativas de la República, por lo tanto se considera que el presente trabajo tiene un diseño exploratorio y su enfoque es cuantitativo y transversal.

El proceso de obtención de datos se dividió en dos fases. La primera consistió en la consulta e interpretación de datos estadísticos sobre accidentabilidad vial en el estado de Tamaulipas y en el municipio de H. Matamoros en el periodo 2005-2015, en zonas urbanas y suburbanas. De acuerdo con el Inegi (2009, p. 7), la zona urbana "es el área habitada o urbanizada que partiendo de un núcleo central, presenta continuidad física en todas direcciones hasta ser interrumpida, en forma notoria por terrenos de uso no urbano como bosques, sembradíos o cuerpos de agua", mientras que la zona suburbana se refiere a "zonas donde la población es de 2,500 a 14,999 habitantes, las viviendas se encuentran dispersas y en algunas ocasiones carecen de algunos servicios" (Inegi, 2009, p. 7). Estas últimas incluyen caminos rurales y carreteras estatales.

En la segunda etapa se aplicó una encuesta a conductores de vehículos del municipio con la finalidad de comprobar, de forma empírica, si en la ciudad de Matamoros Tamaulipas, existen fallas en los procesos administrativos de control respecto a la seguridad vial que pueden resultar favorecedoras para las conductas de riesgo de los conductores de vehículos.

La población de estudio cuenta con las siguientes características:

1. Ser conductor de vehículo-específicamente automóvil-, con la finalidad de obtener datos sobre el ejercicio y experiencias del sujeto, como conductor.

2. Radicar en la cabecera municipal de Heroica Matamoros, Tamaulipas, por ser el lugar de estudio.

3. Tener una edad dentro de un rango de 18 a 26 años, considerando que en México los accidentes viales son la segunda causa de muerte en jóvenes adultos, siendo los ocupantes de vehículo los más afectados (Inegi, 2012). 
Los integrantes de la muestra fueron seleccionados a través de un muestreo no probabilístico y por conveniencia. De esta manera, la muestra quedó conformada por 535 estudiantes universitarios.

La colaboración de los integrantes de la muestra fue de forma voluntaria bajo la garantía de anonimato y confidencialidad en el proceso de investigación. El instrumento utilizado fue un cuestionario, el cual estuvo integrado por 15 ítems, dos de ellos relativos a sus características demográficas y los 13 restantes sobre las variables de estudio. Las preguntas se diseñaron con respuestas cerradas de tipo dicotómicas.

La validación del instrumento se realizó por constructo, con información obtenida en una prueba piloto previa a un total de 120 estudiantes. Las variables se clasificaron en dos categorías: 1) Variables relacionadas con los procesos administrativos de control y 2) Variables sobre el factor humano (conductor).

La confiabilidad del cuestionario se calculó a través del coeficiente KR 20, obteniendo un valor de 0.775 .

No obstante, se destaca la imposibilidad de establecer una correlación precisa entre los datos encontrados y los accidentes de tráfico registrados por las dependencias oficiales de la localidad debido a las siguientes limitantes:

1. Las bases de datos existentes respecto a los accidentes viales en la localidad, no cuentan con información específica respecto a las causas de los mismos.

2. En las dependencias de salud de la localidad, no se registran las causas de las lesiones por accidentes de tráfico.

3. En los reportes de accidentes de tráfico que genera el Departamento de tránsito local, se registran únicamente las causas inmediatas y obvias, no aquellos factores de riesgo asociados a los procesos administrativos de control.

4. Los formatos de accidentes viales que manejan las dependencias que participan en su registro, no están unificados y no se alimenta una sola base de datos, por lo que la información se enuentra dispersa y en ocasiones no disponible para su consulta.

De acuerdo con Planzer (2005), esta problemática es común en los países en vías de desarrollo, los cuales cuentan con escasos métodos de recopilación y procesamiento de datos sobre el tránsito, por lo que las estadísticas reportadas suelen estar incompletas, lo que dificulta el análisis de información para la toma de medidas eficaces respecto a la prevención de accidentes viales.

\section{Resultados}

\section{Primera etapa}

A continuación se presentan los principales indicadores de seguridad vial en la entidad y en el municipio. Esta información ha sido obtenida principalmente de las bases de datos del Inegi, por ser el organismo responsable de la concentración de estos datos a nivel nacional, la cual se realiza con información proveniente de las Direcciones Generales de Tránsito Estatal y Delegaciones de Tránsito Municipal. Cabe mencionar que las cifras correspondientes al año 2015 no son definitivas. 


\section{Indicadores de seguridad vial en Tamaulipas y Matamoros}

En la Tabla 3, se puede observar que los accidentes viales terrestres en la entidad han disminuido gradualmente en la segunda mitad del periodo respecto a la primera. Sin embargo, en el año 2015 se observa un aumento significativo en la siniestralidad vial respecto al año anterior, tanto en el estado, como en Matamoros, lo cual representa un incremento de 3030 y 1349 accidentes, respectivamente. Por otra parte, el porcentaje de accidentes viales terrestres en Matamoros respecto a los registrados en la entidad, se ha incrementado en los últimos cinco años. Esto es preocupante, si además se considera que solo se toman en cuenta los accidentes registrados por las dependencias oficiales, lo cual significa que probablemente la cantidad de accidentes viales sería considerablemente más elevada si se contemplaran los accidentes no reportados. Así mismo, en el estado, más de $93 \%$ de los accidentes han sido registrados en zonas urbanas, mientras que en Matamoros, han sido más de $98 \%$.

Tabla 3: Accidentes viales terrestres en Tamaulipas y Matamoros, por zona

\begin{tabular}{|c|c|c|c|c|c|c|c|}
\hline & \multicolumn{2}{|c|}{ Total de accidentes } & $\begin{array}{c}\text { Accidentes en zona } \\
\text { urbana }\end{array}$ & \multicolumn{2}{c|}{$\begin{array}{c}\text { Accidentes en zona } \\
\text { suburbana }\end{array}$} \\
\hline Año & Tamaulipas & Matamoros & $\begin{array}{c}\text { Matamoros } \\
\text { respecto a } \\
\text { Tamaulipas } \\
\%\end{array}$ & $\begin{array}{c}\text { Tamaulipas } \\
\%\end{array}$ & $\begin{array}{c}\text { Matamoros } \\
\%\end{array}$ & $\begin{array}{c}\text { Tamaulipas } \\
\%\end{array}$ & $\begin{array}{c}\text { Matamoros } \\
\%\end{array}$ \\
\hline 2005 & 28211 & 3735 & 13.24 & 97.81 & 99.38 & 2.19 & 0.62 \\
2006 & 28187 & 2863 & 10.16 & 97.36 & 98.29 & 2.64 & 1.71 \\
2007 & 26902 & 3580 & 13.31 & 97.50 & 98.46 & 2.50 & 1.54 \\
2008 & 25456 & 3020 & 11.86 & 97.05 & 98.71 & 2.95 & 1.29 \\
2009 & 19624 & 2344 & 11.94 & 96.82 & 99.70 & 3.18 & 0.30 \\
2010 & 13082 & 1546 & 11.82 & 95.67 & 100.00 & 4.33 & 0 \\
2011 & 11378 & 1506 & 13.24 & 94.07 & 99.40 & 5.93 & 0.60 \\
2012 & 12808 & 2306 & 18.00 & 93.43 & 99.65 & 6.57 & 0.35 \\
2013 & 13553 & 2572 & 18.98 & 96.73 & 99.49 & 3.27 & 0.51 \\
2014 & 11355 & 2190 & 19.29 & 96.32 & 98.68 & 3.68 & 1.32 \\
2015 & 14385 & 3539 & 24.60 & 94.09 & 99.18 & 5.91 & 0.82 \\
\hline
\end{tabular}

Fuente: Elaboración propia con base en estadísticas del Inegi (2015).

Como se observa en la Tabla 4, si bien existe una disminución en los accidentes viales terrestres en la entidad, el porcentaje de defunciones por esta causa se ha incrementado en la segunda mitad del periodo, particularmente durante los años 2010 y 2014. Por otro lado, respecto a los porcentajes de fatalidades en el municipio respecto a las ocurridas en el estado, puede observarse que el porcentaje más bajo se presentó durante el 2009, sin embargo en el 2015 la cantidad de muertes registradas por esta causa es casi tres veces más. Cabe mencionar que estas estadísticas hacen referencia principalmente a las muertes ocurridas en el sitio del accidente y no a las que ocurren posteriormente como consecuencia del mismo. Esto se debe a que no existen bases de datos donde se integre la información de seguimiento respecto a 
estos eventos que permita tener un mayor acercamiento a la realidad en este rubro, por lo que es altamente probable que la cantidad de muertes a consecuencia de los accidentes viales sea mayor.

Tabla 4: Accidentes viales terrestres, por clase de accidente

\begin{tabular}{|c|c|c|c|c|c|c|c|}
\hline & $\begin{array}{c}\text { Total } \\
\text { accidentes }\end{array}$ & \multicolumn{2}{|c|}{ Accidentes fatales } & \multicolumn{2}{c|}{ Accidentes no fatales } & \multicolumn{2}{c|}{ Accidentes solo daños } \\
\hline Año & Tamaulipas & $\begin{array}{c}\text { Total en } \\
\text { Tamaulipas } \\
\%\end{array}$ & $\begin{array}{c}\text { Matamoros, } \\
\text { respecto al } \\
\text { edo. } \\
\%\end{array}$ & $\begin{array}{c}\text { Total en } \\
\text { Tamaulipas }\end{array}$ & $\begin{array}{c}\text { Matamoros, } \\
\text { respecto al } \\
\text { edo. } \\
\%\end{array}$ & $\begin{array}{c}\text { Matamoros, } \\
\text { respecto al } \\
\text { edo. } \\
\%\end{array}$ \\
\hline 2005 & 28211 & 0.70 & 17.26 & 4816 & 16.18 & 23198 & 12.60 \\
2006 & 28187 & 0.63 & 13.48 & 4895 & 8.42 & 23114 & 10.50 \\
2007 & 26902 & 0.65 & 7.47 & 4498 & 12.43 & 22230 & 13.53 \\
2008 & 25456 & 0.71 & 11.11 & 5576 & 10.76 & 19700 & 12.18 \\
2009 & 19624 & 0.87 & 4.68 & 4718 & 13.67 & 14735 & 11.48 \\
2010 & 13082 & 1.34 & 9.71 & 3658 & 15.86 & 9249 & 10.26 \\
2011 & 11378 & 1.25 & 11.97 & 3637 & 14.13 & 7599 & 12.83 \\
2012 & 12808 & 1.16 & 12.08 & 3367 & 25.16 & 9292 & 15.51 \\
2013 & 13553 & 1.31 & 17.51 & 3416 & 26.46 & 9960 & 16.44 \\
2014 & 11355 & 1.73 & 13.71 & 155 & 25.42 & 8003 & 17.01 \\
2015 & 14385 & 1.18 & 12.94 & 2924 & 25.58 & 11291 & 24.52 \\
\hline
\end{tabular}

Fuente: Elaboración propia con base en datos del Inegi (2015).

Respecto a los accidentes no fatales, mientras que en Tamaulipas la cantidad de estos accidentes tiende a disminuir, a partir del 2008 se observa un incremento gradual en el porcentaje de aquellos registrados en el municipio, de tal forma que en el periodo del 2012 al 2015, los accidentes no fatales ocurridos en Matamoros, representan más de $25 \%$ de los casos registrados en todo el estado. $\mathrm{Al}$ respecto, es importante aclarar que existen casos donde el conductor responsable del accidente se da a la fuga del lugar de los hechos, lo que implica que sus lesiones y la de las personas que lo acompañan no siempre son registradas en las estadísticas.

Por último, los accidentes viales que generaron solo daños materiales presentaron una tendencia a la baja en el estado, exceptuando el 2015, donde se observa un incremento significativo respecto al año anterior con 3288 casos más, de los cuales casi 25\% corresponde al municipio de Matamoros. Así mismo, en el año 2013 se presentó el mayor porcentaje de fatalidades y de accidentes no fatales en Matamoros respecto al total registrado en el estado, dentro del periodo de estudio.

Como se plasma en las tablas 5 y 6 , la causa que principalmente ha sido identificada en los accidentes viales terrestres tanto del estado como del municipio, corresponde al conductor del vehículo. Respecto a los accidentes fatales en Matamoros, esta causa llega a ser la única registrada en los años 2005, 2006, y del 2008 al 2011, mientras que en Tamaulipas es superior a 90\% en los tres últimos años del periodo de estudio. 
Tabla 5: Accidentes viales terrestres en Tamaulipas, por causa

\begin{tabular}{ccccccc}
\hline Año & $\begin{array}{c}\text { Conductor } \\
\text { respecto } \\
\text { al total de } \\
\text { accidentes } \\
\text { \% }\end{array}$ & $\begin{array}{c}\text { Conductor } \\
\text { respecto a las } \\
\text { fatalidades } \\
\text { \% }\end{array}$ & $\begin{array}{c}\text { Falla del } \\
\text { vehículo } \\
\text { respecto } \\
\text { al total de } \\
\text { accidentes } \\
\text { \% }\end{array}$ & $\begin{array}{c}\text { Peatón / } \\
\text { pasajero res- } \\
\text { pecto al total } \\
\text { de accidentes } \\
\text { \% }\end{array}$ & $\begin{array}{c}\text { Malas con- } \\
\text { diciones del } \\
\text { camino respec- } \\
\text { to al total de } \\
\text { accidentes } \\
\text { \% }\end{array}$ & $\begin{array}{c}\text { Otra respecto al } \\
\text { total de accidentes } \\
\%\end{array}$ \\
\hline 2005 & 59 & 66 & 0.50 & 0.24 & 0.10 & 40.46 \\
2006 & 47 & 56 & 0.50 & 0.29 & 0.12 & 51.73 \\
2007 & 57 & 67 & 0.35 & 0.24 & 0.16 & 42.10 \\
2008 & 44 & 64 & 0.58 & 0.32 & 0.17 & 54.72 \\
2009 & 54 & 54 & 0.50 & 0.33 & 0.19 & 44.64 \\
2010 & 34 & 50 & 0.99 & 0.60 & 0.22 & 64.50 \\
2011 & 97 & 93 & 0.86 & 0.56 & 0.47 & 1.19 \\
2012 & 97 & 87 & 0.56 & 0.59 & 0.51 & 1.24 \\
2013 & 98 & 90 & 0.55 & 0.61 & 0.41 & 0.77 \\
2014 & 98 & 95 & 0.80 & 0.39 & 0.27 & 0.51 \\
2015 & 98 & 95 & 1.17 & 0.26 & 0.31 & 0.45 \\
\hline
\end{tabular}

Fuente: Elaboración propia con base en los datos registrados por el Inegi (2015).

Tabla 6: Accidentes viales terrestres en Matamoros, por causa

\begin{tabular}{ccccccc}
\hline Año & $\begin{array}{c}\text { Conductor res- } \\
\text { pecto al total } \\
\text { de accidentes } \\
\text { \% }\end{array}$ & $\begin{array}{c}\text { Conductor } \\
\text { respecto a las } \\
\text { fatalidades } \\
\text { \% }\end{array}$ & $\begin{array}{c}\text { Falla del vehí- } \\
\text { culo respecto } \\
\text { al total de } \\
\text { accidentes } \\
\text { \% }\end{array}$ & $\begin{array}{c}\text { Peatón / pasa- } \\
\text { jero respecto } \\
\text { al total de } \\
\text { accidentes } \\
\text { \% }\end{array}$ & $\begin{array}{c}\text { Malas condicio- } \\
\text { nes del camino } \\
\text { respecto al total } \\
\text { de accidentes } \\
\text { \% }\end{array}$ & $\begin{array}{c}\text { Otra } \\
\text { respecto } \\
\text { al total de } \\
\text { accidentes } \\
\text { \% }\end{array}$ \\
\hline 2005 & 99.95 & 100 & 0.03 & 0.00 & 0.00 & 0.03 \\
2006 & 99.93 & 100 & 0.00 & 0.07 & 0.00 & 0.00 \\
2007 & 99.69 & 92.31 & 0.03 & 0.28 & 0.00 & 0.00 \\
2008 & 99.74 & 100 & 0.00 & 0.20 & 0.03 & 0.03 \\
2009 & 99.96 & 100 & 0.00 & 0.04 & 0.00 & 0.00 \\
2010 & 99.94 & 100 & 0.00 & 0.06 & 0.00 & 0.00 \\
2011 & 98.80 & 100 & 0.07 & 0.13 & 0.00 & 1.00 \\
2012 & 99.74 & 88.89 & 0.04 & 0.09 & 0.00 & 0.13 \\
2013 & 98.25 & 96.77 & 0.04 & 0.16 & 0.16 & 1.40 \\
2014 & 98.49 & 96.30 & 0.50 & 0.18 & 0.27 & 0.55 \\
2015 & 97.49 & 95.45 & 2.03 & 0.14 & 0.23 & 0.11 \\
\hline
\end{tabular}

Fuente: Elaboración propia con base en los datos registrados por el Inegi (2015).

En lo que respecta al tipo de accidente, los tres principales son: 1) colisión entre vehículos, 2) colisión con objeto fijo y 3) atropellamiento. Cabe señalar que el primero es superior a $60 \%$ en ambos casos. Por otro lado, aunque la colisión con motocicleta no está entre los primeros tres tipos de accidentes viales, llama la atención que el porcentaje de estos accidentes se ha incrementado en Tamaulipas de $1.40 \%$ inicial a $6.10 \%$ al final del periodo, mientras que en Matamoros, pasó de $1.07 \%$ a $3.19 \%$. 
Respecto a las fatalidades ocasionadas por accidentes viales en el estado, al inicio del periodo de estudio el tipo de accidente con mayor frecuencia fue la colisión entre vehículos, seguida por atropellamiento y volcaduras. Mientras que en la segunda mitad, el atropellamiento se ha registrado como la primera causa de muerte. En lo concerniente al municipio, en los últimos cinco años, el tipo de accidente identificado en la mayoría de las defunciones ha sido el atropellamiento, seguido por colisión entre vehículos, a excepción del 2015, donde se ubica en primer lugar, la colisión con objeto fijo.

\section{Segunda etapa}

Los datos obtenidos en el proceso de aplicación del cuestionario respecto a las características demográficas de la muestra y su distribución son los siguientes. Cincuenta y tres por ciento de los participantes son del género masculino, mientras que $47 \%$ pertenecen al género femenino. Respecto a la edad, $33 \%$ de la muestra se encuentra en un rango entre 18 y 20 años, $18 \%$ entre 21 y 23 años y $49 \%$ restante entre 24 y 26 años.

En lo concerniente a las características de la muestra en el ejercicio de conducción, $88 \%$ tienen de 1 a 5 años de experiencia como conductores, mientras que $81 \%$ de la muestra afirmó que el número aproximado de veces que conducen en un día es de 3 a 4 ocasiones, no obstante, solo $66 \%$ de ellos cuenta con licencia para conducir y de este porcentaje, $15 \%$ no cuenta con su licencia vigente.

Además, de los 353 jóvenes que han tramitado su licencia de manejo, 105 de ellos (30\%), informaron no haber tomado un curso de manejo previo. Cabe señalar, que aunque $70 \%$ de los jóvenes afirmaron haber tomado clases para conducir, la realidad es que no existe en la actualidad una escuela certificada de manejo en la localidad, y que de haberlo hecho, probablemente fue a través de métodos informales con personas no acreditadas, sin garantía de la aplicación correcta de las reglas de vialidad. Por otro lado, $50 \%$ de los jóvenes encuestados manifestaron no haber presentado un examen teórico o práctico previo a la adquisición de la licencia de conducir. Así mismo, 98\% comentó no haberse realizado un examen médico para descartar problemas de visión antes de iniciar su ejercicio como conductor como requisito para obtener su licencia.

Por otro lado, cabe señalar que si bien, $48 \%$ de los encuestados asegura no haber infringido una regla de tránsito, se debe considerar que $62 \%$ de la muestra aseveró no conocer el reglamento de tránsito de su localidad. Esto significaría que algunas personas pudieran haber cometido infracciones sin darse cuenta de que lo hicieron.

Por otra parte, $52 \%$ reconoce haber infringido las reglas de vialidad como conductor por lo menos en una ocasión en los últimos meses. Sin embargo, de ese porcentaje, $42 \%$ aseguró no haber sido infraccionado por una autoridad vial al cometer dichas infracciones.

De la misma forma, $43 \%$ de la muestra, es decir, 230 de los jóvenes manifestó haber sufrido por lo menos un percance vial mientras conducía durante los últimos tres meses, de los cuales solo en $40 \%$ de los casos hubo la intervención de las autoridades de tránsito local. Es decir, en $60 \%$ de los eventos ocurridos no quedó asentado antecedente alguno. Por último, en $35 \%$ de los eventos ocurridos, estuvo al menos un vehículo extranjero involucrado. 
De lo anterior, se identifican situaciones de riesgo o, según Bird y Germain (1990), actos y condiciones subestándares que aumentan la probabilidad de ocurrencia de accidentes viales, sobre los cuales las autoridades competentes tienen injerencia. Estos se describen en la Tabla 7.

Tabla 7: Conductas de riesgo que pueden incrementar la probabilidad de ocurrencia de accidentes viales

\begin{tabular}{lcc}
\hline Conducta de riesgo identificada & $\begin{array}{c}\text { Responsabilidad de la } \\
\text { administración }\end{array}$ & $\begin{array}{c}\text { Responsabilidad del } \\
\text { conductor }\end{array}$ \\
\hline
\end{tabular}

Conducir vehículos ilegales Tránsito

Operar un vehículo sin poseer licencia de conducir o con licencia vencida

Conducir sin haber adquirido capacitación previa

Operar un vehículo sin antes descartar problemas de visión

Infracciones de tránsito
Aplicar medidas de control para el cumplimiento de la normatividad. Establecer mecanismos que promuevan la legalización de vehículos extranjeros.

Asegurar el conocimiento del reglamento de tránsito antes de expedir una licencia de conducir a través de un examen teórico. Promover la cultura vial en todos los sectores de la población a través de programas de educación continua.

Programar actividades de inspección periódicas (retenes).

Ejecutar las sanciones administrativas o económicas pertinentes.

Exigir la aprobación de un examen de manejo práctico antes de expedir licencias de conducir.

Promover la creación de escuelas de manejo certificadas en la localidad.

Exigir la aprobación de un examen de la vista antes de expedir licencias de conducir y al renovarla.

Contar con suficientes policías viales y ubicarlos en zonas y horarios estratégicos. Gestionar la instalación de cámaras de video para monitoreo vial.

Mantener de forma visible y en buen estado las señales de tránsito.
Legalizar los vehículos a través de la compra de vehículos nacionales, o la regularización o nacionalización de vehículos de procedencia extranjera.

Consultar el reglamento de tránsito antes de iniciar su ejercicio como conductor.

Tramitar licencia de conducir antes de iniciar su ejercicio como conductor.

Mantener su licencia de conducir vigente.

Tomar clases de manejo que le permitan adquirir las habilidades necesarias antes de solicitar la licencia de conducir.

Realizarse exámenes médicos periódicos para descartar problemas de visión.

Conocer el reglamento de tránsito local y respetarlo al hacer uso de la vía.

Fuente: Elaboración propia. 


\section{Discusión}

Si bien, los accidentes viales terrestres en zonas urbanas y suburbanas han disminuido en la entidad a través de los años, la tasa de mortalidad por estos eventos se ha incrementado y continúa siendo mayor a la media nacional (CONAPRA, 2014; Inegi, 2015). Adicionalmente, los accidentes viales han aumentado significativamente durante el año 2015 tanto en el estado, como en el municipio, presentando mayor incidencia en las zonas urbanas. Así mismo, los accidentes no fatales y de solo daños registrados en el municipio durante 2015, representan alrededor de $25 \%$ de los registrados en la entidad.

La principal causa asociada a estos eventos, en ambos casos, ha sido el conductor, lo cual coincide con lo expuesto por Arias (2011) y Alfaro-Basso, (2008). De la misma manera, se comprueba la primera hipótesis declarada en el presente estudio: "La principal causa asociada a la ocurrencia de accidentes viales en el municipio de Matamoros Tamaulipas, corresponde a conductas de riesgo de los conductores de vehículos, que ponen en riesgo su integridad y la de terceros".

El principal tipo de accidente vial en el municipio y en el estado, es la colisión de vehículos; mientras que el atropellamiento ha sido el primero relacionado a fatalidades durante la segunda mitad del periodo en ambos casos, a excepción del 2015, donde en el municipio se ubican en primer lugar, las colisiones con objeto fijo.

Por otro lado, los procesos administrativos de control en materia de seguridad vial en el municipio, presentan serias deficiencias, lo cual se asemeja al caso de Colombia señalado por Ferrer et al. (2013). Según los resultados del presente estudio las fallas detectadas se refieren principalmente a la expedición de licencias de manejo sin que el solicitante deba comprobar su conocimiento teórico y habilidades prácticas como conductor, ni garantizar que posea un estado físico óptimo, particularmente respecto a su visión. Otra falla es en relación con la falta de mecanismos de control que aseguren que el conductor conozca previamente el reglamento de tránsito de su localidad de manera que le brinde el conocimiento básico sobre el correcto uso de las vías.

Por otro lado, también se encontró escasez de elementos de vigilancia vial que aseguren la ejecución de sanciones administrativas o económicas para el infractor, que permitan disminuir la probabilidad de impunidad, y por ende, la probable repetición de la conducta de riesgo. En este sentido, la falta de control sobre la legalización de vehículos provoca un ambiente propicio para evadir la responsabilidad ante un accidente de tráfico.

Lo anterior, permite corroborar la segunda hipótesis de investigación: "En la ciudad de Matamoros Tamaulipas, existen fallas en los procesos administrativos de control, lo cual representa un factor de riesgo asociado a los accidentes viales, ya que favorecen las conductas de riesgo".

Tal como lo menciona Planzer (2005), antes de establecer acciones y programas de seguridad vial, las regiones deben realizar un diagnóstico previo que brinde información real sobre la problemática local, de tal manera que la toma de decisiones se realice con base en información verídica y no por meras suposiciones. Por eso debe tomarse en cuenta el contexto y el tiempo en el que se realizan las intervenciones.

En el caso del municipio de Matamoros, Tamaulipas, puede evidenciarse que detrás de las conductas humanas, existen procesos administrativos deficientes, tal como lo pronuncian Bird y Germain, (1990), por lo que el propio sistema, debe ser considerado 
como un factor que influye sobre el comportamiento del factor humano de manera positiva o negativa. De esta manera el sistema debe ser incluido en los procesos de prevención de accidentes viales como un factor implícito, tal como lo exponen los grupos de trabajo de conAPrea (citados por Mendoza, Quintero y Mayoral, 2003).

En este sentido, Sánchez (2008), demuestra que la conducta puede ser modificada a partir de la aplicación de un sistema de sanciones adecuado (efecto sancionador percibido). Cabe mencionar que en México, uno de los problemas sociales que existen es la corrupción, lo cual podría representar un obstáculo para que el sistema de sanciones sea efectivo.

No obstante, la meta a largo plazo es la cultura vial observable en todos los usuarios de las vías y no solo la reacción por coerción. La realidad es que para lograrlo el primer paso debería ser el establecimiento de métodos de control efectivos para asegurar el cumplimiento elemental de las reglas de tránsito, lo cual indudablemente, es responsabilidad de la administración pública.

Por lo tanto, con base en la información consultada y los resultados obtenidos a través de la aplicación del cuestionario, se propone el modelo de multicausalidad de accidentes viales en la Figura 4.

Figura 4: Modelo de multicausalidad de accidentes viales

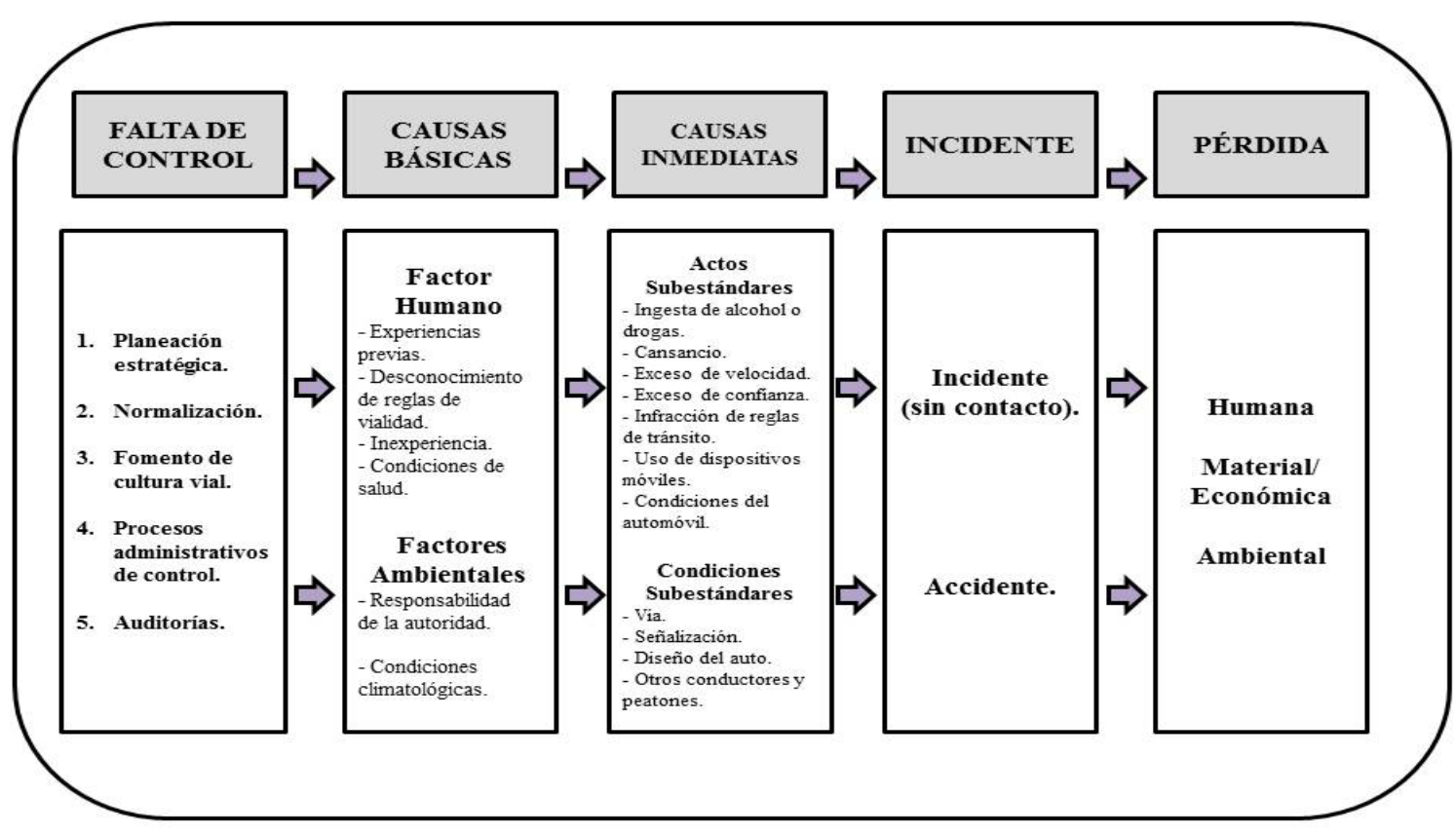

Fuente: Elaboración propia. Adaptación del modelo de Bird (Bird y Germain, 1990).

La falta de control desde el sistema incluye varios aspectos, como a) la planeación estratégica en la construcción y distribución de vialidades; $b$ ) la creación o modificación de la normativa de tal forma que se eliminen las obsolescencias y se cubran los huecos legales que incrementan la posibilidad de riesgo; $c$ ) el fomento de cultura y educación vial debe ser una tarea abordada por las autoridades, pues este fenómeno es un proceso en el que debe trabajarse en conjunto de forma cotidiana y no solamente en campañas 
esporádicas; $d$ ) el sistema de multas referido a las sanciones económicas o legales que deben ejercerse como consecuencia de conductas no deseadas, así como los procesos que permiten mantener un control sobre los conductores de vehículos, como la expedición de licencias de manejo; por último, e) las auditorías de los puntos críticos de vialidad y del buen funcionamiento de las instituciones en materia de seguridad vial permiten tomar acciones preventivas en la disminución de eventos de tráfico.

Por otro lado, adoptar programas que mejoren los procesos de expedición de licencias es una buena opción para reducir los riesgos. En países como Canadá y Estados Unidos, se ha puesto en marcha el programa de "Permiso de Conducir Gradual-(PCG)", que consiste en que durante los primeros meses de ejercicio de un nuevo conductor, este es acompañado por un supervisor, posteriormente empieza una fase de conducción no supervisada pero restringida a horarios o espacios donde el riesgo de colisión sea mínimo. Por último, se otorga el permiso de conducir sin restricciones. Novoa, Pérez y Borrell (2009), consideran que este tipo de programas han demostrado una reducción de $31 \%$ en la cantidad de colisiones y de 7 a $19 \%$ en las fatalidades.

Así mismo, Gómez, Pérez e Hidalgo (2014), afirman que en países como Estados Unidos, Francia, Austria, Inglaterra y Gales la reducción de los límites máximos permisibles a $0.05 \mathrm{~g} / \mathrm{dL}$, de alcoholemia en conductores de vehículos ha generado una disminución en diversos indicadores de seguridad vial, especialmente en fatalidades. Mientras que en otros lugares como Australia y Países Bajos, un progreso similar se atribuye a las campañas publicitarias y la aplicación de la legislación de manera rigurosa.

Con acciones como estas, puede reducirse la persistencia de condiciones inherentes al factor humano, como la sensación del individuo de que puede infringir las reglas sin obtener un castigo o consecuencia por ello, el tener una licencia de manejo sin conocer las reglas de tránsito de su localidad, o tener problemas visuales, auditivos, etc., que incrementen el riesgo de sufrir una lesión o generar un accidente vehicular. Al mismo tiempo, se tendría impacto sobre muchos de los factores ambientales que contribuyen a la ocurrencia de este tipo de eventos. Por consecuencia, se disminuyen los actos y las condiciones subestándares, no dando lugar al incidente o accidente ni a las pérdidas que estos conllevan.

Mientras la investigación de accidentes viales se quede a nivel de causas inmediatas, no se contará con información necesaria para atacar la causa raíz de los mismos.

\section{Conclusiones}

Si bien, el sistema, entendido como los procesos administrativos de control respecto a la seguridad vial, no es el único responsable de los accidentes de tráfico, es indudable que existe una marcada deficiencia en su funcionamiento esencial, que es establecer medios de control efectivos para disminuir los riesgos asociados a los accidentes viales. Específicamente su incidencia radica sobre el factor humano, el cual ha sido identificado como el principal causante de dichos eventos de tráfico.

Por lo tanto, puede decirse que en la medida que estos procesos sean efectivos en su actuar, se manifestará su impacto positivo en la reducción de los accidentes viales y por lo tanto, en sus consecuencias sobre la salud de la población. 
Por otra parte, se hace pertinente continuar con estudios sobre el tema aplicando el instrumento en muestras más extensas y en otros contextos correlacionando los diversos factores que intervienen en la ocurrencia de accidentes viales para conocer en qué medida influye cada uno de ellos sobre los mismos, de tal manera que se profundice en sus causas más allá de la superficie, la cual solamente representa la punta del iceberg.

Sin embargo, mientras no se enriquezcan y homologuen los registros de investigación de accidentes, y se cuente con bases de datos completas alimentadas por todas las dependencias que intervienen en los eventos de tráfico, los investigadores seguirán enfrentando serios obstáculos para la obtención de datos en su tarea de realizar aportes científicos sobre medidas efectivas de seguridad vial.

\section{Referencias}

Adriasola, G., Olivares, C. y Díaz, C. (1972) Prevención de accidentes del tránsito. Bol of Sanit Panam, 72(1), 1-18.

Aguilar-Zinser, J. (2010). La situación actual de los accidentes en el mundo. Simposio. Gaceta Médica de México, 146(6), 384-388.

Alemany, R., Ayuso, M. y Guillén, M. (2013). Impact of road traffic injuries on disability rates and long-term care costs in Spain. Accidents Analysis $\mathcal{E}$ Prevention, 60, 95-102.

Alfaro-Basso, D. (2008). Problemática sanitaria y social de la accidentalidad del transporte terrestre, Rev. Perú Med. Exp Salud Pública, 25(1), 133-137.

Arias, W. (2011). Una reseña introductoria a la psicología del tránsito. Revista de Psicología, 13(1), 113-119.

Arreola C., Guzmán J., Esquivel, A. y Mock, C. (2008). Traffic related deaths in Nuevo Leon, Mexico: causes and associated factors. Salud Pública de México, 50(1), 48-54.

Arreola, C., Herrera, A., Cruz, O. de la y Mock, C. (2003). Análisis de la mortalidad por accidentes viales en la ciudad de Monterrey. Qué hemos aprendido y estrategias a implementar, TRAUMA, 6(1), 4-14.

Ávila, L., Medina, C., Pérez, R., Híjar, M., Aracena, B., Hidalgo, E. y Palma, O. (2008). Prevalencia de accidentes de tránsito no fatales en México: resultados de la ENSANut 2006. Salud Pública de México, 50(1), 38-47.

Bird, F. y Germain, G. (1990). Liderazgo Práctico en el Control de Pérdidas. Canadá: ILCI.

Bustos, E., Cabrales, R., Cerón, M. y Naranjo, M. (2014). Epidemiología de lesiones no intencionales en niños: revisión de estadísticas internacionales y nacionales. Boletín Médico del Hospital Infantil México, 71(2), 68-75.

Cable News Network México (cnN México). (18 de diciembre de 2014). ¿Cuál es la causa que más muertes provoca en México y el mundo? Recuperado de http://mexico.cnn.com/salud/2014/12/18/cual-es-la-causa-que-mas-muertes-provoca-enmexico-y-el-mundo

Cabrera, G., Velásquez, N. y Valladares, M. (2009). Seguridad vial, un desafío de salud pública en la Colombia del siglo xxi. Revista Facultad Nacional Salud Pública, $27(2), 218-225$. 
Calafat, A., Adrover, D., Juan, M. y Blay, N. (2008). Relación del consumo de alcohol y drogas de los jóvenes españoles con la siniestralidad vial durante la vida recreativa nocturna en tres comunidades autónomas en 2007. Revista Española de Salud Pública, 82(3), 323-331.

Consejo Nacional para la Prevención de Accidentes (CONAPRA). (2014). Perfil estatal Tamaulipas 2013. México: Autor.

Cortés, J. M. (2001). Seguridad e higiene en el trabajo. México: Alfaomega.

Dirección General de Tránsito Municipal. (s.f.). Factores de riesgo. Recuperado de http:/ / docplayer.es/2070671-Factores-de-riesgo-sp1-direccion-general-de-transito-municipal.html

Donas, S. (2001). Protección, riesgo y vulnerabilidad. Sus posibles aplicaciones en la promoción, prevención, tratamiento y rehabilitación de la salud integral de los adolescentes y las adolescentes. En S. Donas (Comp.), Adolescencia y juventud en América Latina (pp. 489-499). Costa Rica: Libro Universitario Regional.

Ferrer, A., Smith, R., Espinosa, O., Cuellar, M. y Raffo, V. (2013). Análisis de la capacidad de gestión de la seguridad vial en Colombia. Bogotá, Colombia: World Bank.

Gallego, R., Peña, S. de la, Muñoz, R., Taddia, A., Bustamante, C. y Café, E. (2015). Seguridad vial infantil. Uso de los sistemas de retención. Análisis de la situación en América Latina y el Caribe. Washington, Estados Unidos de América: Fundación Mapfre.

Godoy, L., Escaudar, C., Jaca, R. y Pinto, F. (2001). Revisión crítica de algunas teorías de accidentes asociadas a la infraestructura. Revista Internacional de Desastres Naturales, Accidentes e Infraestructura Civil, 1(2), 127-139.

Gómez, L., Pérez, R. e Hidalgo, E. (2014). Impacto de la reforma en la legislación sobre consumo de alcohol y conducción en Guadalajara y Zapopan, Jalisco, México: una mirada en el corto plazo. Cuadernos de Saúde Pública, 30(6), 1281-1292.

Guanche, H., Martínez, C. y Gutiérrez, F. (2007). Efecto del alcohol en la capacidad de conducción de vehículos automotores. Revista Cubana de Salud Pública, 33(1), 1-6.

Instituto Nacional de Estadística y Geografía. (Inegi). (2009). Síntesis metodológica de la estadística de accidentes de tránsito terrestre en zonas urbanas y suburbanas (ATUS). México: Autor.

Instituto Nacional de Estadística y Geografía. (Inegi). (2010). Censo de Población y Vivienda. México: Autor.

Instituto Nacional de Estadística y Geografía. (Inegi). (2012). Accidentes de tránsito terrestre en zonas urbanas y suburbanas. México: Autor.

Instituto Nacional de Estadística y Geografía. (Inegi). (2015). Estadísticas de accidentes de tránsito terrestre. México: Autor.

Kalantar, M. H., Dadgar, E. y Ebrahimi, A. (2014). Curbing road traffic accidents - The major cause of facial fractures. Internatinal Journal of Emergency Mental Health and Human Resistance, 16(2), 69-70.

Martínez, C. (2012). Los vehiculos usados de procedencia extranjera en México (Documento de trabajo núm. 142). México: Centro de Estudios Sociales y de Opinión Pública.

Medina, M., Borja, G. y Flores, M. V. (2014). Manejo de emergencia a víctimas de accidentes de tránsito. Ecuador: EDIMEc. 
Meliá, J., Ricarte, J. y Arnedo, M. (1998). La psicología de la seguridad (I): Una revisión de los modelos procesuales de inspiración mecanicista. Revista de Psicología General y Aplicada, 51(1), 37-54.

Mendoza, A., Quintero, F. y Mayoral, E. (2003). Seguridad vial en carreteras (Publicación técnica núm. 224). México: Secretaría de Comunicaciones y Trasportes, Instituto Mexicano del Transporte.

Morales-Soto, N., Alfaro-Basso, D. y Gálvez-Rivero, W. (2010). Aspectos psicosociales y accidentes en el transporte terrestre. Revista Peruana de Medicina Experimental y Salud Pública, 27(2), 267-272.

Novoa, A., Pérez, K. y Borrell, C. (2009). Efectividad de las intervenciones de seguridad vial basadas en la evidencia: una revisión de la literatura. Gaceta Sanitaria, 23(6), 553.e1-553.e14.

Organización Mundial de la Salud (омs). (2015a). Informe sobre la situación mundial de la seguridad vial 2015. Francia: Autor.

Organización Mundial de la Salud (oms). (2015b). Lesiones causadas por el tránsito. España: Autor.

Organización Panamericana de la Salud (OPS). (2013). Informe sobre la situación mundial de la seguridad vial. Recuperado de http://www.who.int/iris/bitstream/10665/83798/1/WHO_NMH_VIP_13.01_spa.pdf

Pérez-Núñez, R., Híjar, M., Celis, A., e Hidalgo-Solórzano, E. (2014). El estado de las lesiones causadas por el tránsito en México: evidencias para fortalecer la estrategia mexicana en seguridad vial. Revista de Saúde Pública, 30(5), 911-925.

Planzer, R. (2005). La seguridad vial en la región de América Latina y el Caribe. Situación actual y desafíos. En CEPAL (Ed.), Serie recursos naturales e infraestructura (núm. 102, pp. 1-71). Chile: Naciones Unidas.

Programa Sectorial de Salud. (2014). Programa de acción especifico seguridad vial (20132018). México: Autor.

Quistberg, A., Miranda, J. y Ebel, B. (2010). Reduciendo el trauma y la mortalidad asociada a los accidentes de tránsito en los peatones en el Perú: Intervenciones que pueden funcionar. Revista Peruana de Medicina Experimental y Salud Pública, 27(2), 248-254.

Rey, J., Rosales, E. y Egoavil, M. (2009). Somnolencia y cansancio durante la conducción: Accidentes de tránsito en las carreteras de Perú. Acta Médica Peruana, 26(1), 48-54.

Rosales, E., Egoavil, M., Durand, I., Montes, N., Flores, R., Rivera, S.,... y Rey, J. (2009). Accidentes de carretera y su relación con cansancio y somnolencia en conductores de ómnibus. Revista Médica Herediana, 20(2), 48-59.

Roth, K. (5 al 6 de noviembre de 2016). Panel paper: Weather, traffic accidents, and exposure to climate change. Trabajo presentado en la $38^{\text {th }}$ Annual Fall Research Conference, Indiana University, Washington. Recuperado de https://appam.confex. com/appam/2016/webprogram/Paper17709.html

Sánchez, F. (2008). Actitudes frente al riesgo vial. Psychosocial Intervention, 17(1), 45-59. Secretaría de Salud (ss). (2012). Causan accidentes viales 24 mil muertes cada año. México: Autor.

Secretaría de Salud (ss). (2015). Informe sobre la situación de seguridad vial, México 2015. México: Autor. 
Vázquez, R. (2004). Causas de los accidentes de tránsito desde una visión de la medicina social. El binomio alcohol-tránsito. Revista Médica del Uruguay, 20, 178-186.

White, K., Hyde, M., Walsh, S. y Watson, B. C. (2010). Mobile phone use while driving: An investigation of the beliefs influencing driver's hands-free and hand-held mobile phone use. Transportation Research Part F: Traffic Psychology and Behaviour, 13(1), 9-20.

World Health Organization (wHo). (2013). Global status report on road safety 2013. Supporting a decade of action. Suiza: Autor.

Zamorano, B., Peña, F., Parra, V., Velázquez, Y. y Vargas, J. (2015). Contaminación por ruido en el centro histórico de Matamoros. Acta Universitaria, 25(5), 20-27. doi: $10.15174 /$ au.2015.819.

Yolanda Velázquez Narváez

Mexicana. Licenciada en Seguridad e Higiene Industrial en la Universidad Autónoma de Tamaulipas, Maestra en Administración de Negocios por la Universidad Tecmilenio y Doctora en Educación por la Universidad de Baja California. Profesora de tiempo completo en la Unidad Académica Multidisciplinaria de Matamoros de la Universidad Autónoma de Tamaulipas (UAMM-UAT). Líneas de investigación: prevención de riesgos, conductas y cognición en escenarios sociales y organizacionales. Publicaciones: a) "Prevalencia del nivel de estrés académicos en universitarios, con diferencia de género", b) "Rol laboral como factor de riesgo psicosocial en los profesionales de la salud" y c) "Contaminación acústica por tránsito vehicular en la frontera de México".

Benito Zamorano González

Mexicano. Licenciado en Seguridad e Higiene Industrial en la Universidad Autónoma de Tamaulipas y Maestro en Ciencias de Salud Ocupacional por la Universidad Autónoma de Tamaulipas. Profesor de tiempo completo en la Unidad Académica Multidisciplinaria de Matamoros de la Universidad Autónoma de Tamaulipas (UAMM-UAT). Líneas de investigación: prevención de riesgos y psicología. Publicaciones: a) "Adicción y factores determinantes en el uso problemático del internet en una muestra de jóvenes universitarios", b) "Rol laboral como factor de riesgo psicosocial en los profesionales de la salud" y c) "Contaminación acústica por tránsito vehicular en la frontera de México".

Lucía Ruíz Ramos

Mexicana. Licenciada en Psicología en la Universidad Autónoma de Tamaulipas y Doctora en Psicología Aplicada por la Universidad de Sevilla. Profesora de tiempo completo en la Unidad Académica Multidisciplinaria de Matamoros de la Universidad Autónoma de Tamaulipas (UAMM-UAT). Líneas de investigación: prevención de riesgos, conductas y cognición en escenarios sociales y organizacionales. Publicaciones: a) "Prevalencia del nivel de estrés académicos en universitarios, con diferencia de género", b) "Rol laboral como factor de riesgo psicosocial en los profesionales de la salud" y $c$ ) "Autoestima y obesidad en alumnos y alumnas de nivel secundaria". 